\title{
Anosognosia in Very Mild Alzheimer's Disease but Not in Mild Cognitive Impairment
}

\author{
E. Kalbe ${ }^{a}$ E. Salmon ${ }^{\text {b }}$ D. Peranic V. Holthoff ${ }^{d}$ S. Sorbi ${ }^{\mathrm{e}} \quad$ A. Elsner ${ }^{\mathrm{a}}$ \\ S. Weisenbach ${ }^{a}$ M. Brand ${ }^{f}$ O. Lenz ${ }^{a} \quad J_{\text {Kessler }}{ }^{\mathrm{a}} \quad$ S. Luedecke ${ }^{d} \quad$ P. Ortellic \\ K. Herholz ${ }^{a}$ \\ ${ }^{a}$ Department of Neurology, University Hospital, and Max Planck Institute for Neurological Research, Cologne, \\ Germany; ${ }^{b}$ Cyclotron Research Centre, University of Liège, Liège, Belgium; ${ }^{C}$ Vita Salute San Raffaele \\ University, and Department of Neurology San Raffaele-Ville Turro, Milan, Italy; ${ }^{d}$ Department of Psychiatry \\ and Psychotherapy, Dresden University of Technology, Dresden, Germany; ${ }^{\mathrm{e}}$ Department of Neurological and \\ Psychiatric Sciences, University of Florence, Florence, Italy; ${ }^{f}$ Department of Physiological Psychology, University \\ of Bielefeld, Bielefeld, Germany
}

\section{Key Words}

Anosognosia $\cdot$ Self-awareness $\cdot$ Insight $\cdot$ Dementia $\cdot$

Cognitive dysfunction $\cdot$ Alzheimer's disease $\cdot$ Mild

cognitive impairment

\begin{abstract}
Objective: To study awareness of cognitive dysfunction in patients with very mild Alzheimer's disease (AD) and subjects with mild cognitive impairment (MCl). Methods: A complaint interview covering 13 cognitive domains was administered to $82 \mathrm{AD}$ and $79 \mathrm{MCl}$ patients and their caregivers. The patient groups were comparable according to age and education, and Mini Mental State Examination (MMSE) scores were $\geq 24$ in all cases. The discrepancy between the patients' and caregivers' estimations of impairments was taken as a measure of anosognosia. Results: Self-reports of cognitive difficulties were comparable for $\mathrm{AD}$ and $\mathrm{MCl}$ patients. However, while in comparison to caregivers $\mathrm{MCl}$ patients reported significantly more cognitive impairment $(p<0.05), A D$ patients complained significantly less cognitive dysfunctions $(p<0.001)$. Conclusions: While most $\mathrm{MCl}$ patients
\end{abstract}

tend to overestimate cognitive deficits when compared to their caregiver's assessment, AD patients in early stages of disease underestimate cognitive dysfunctions. Anosognosia can thus be regarded as a characteristic symptom at a stage of very mild AD (MMSE $\geq 24$ ) but not $\mathrm{MCl}$. Accordingly, medical history even in mildly affected patients should always include information from both patient and caregiver.

Copyright (C) 2005 S. Karger AG, Basel

\section{Introduction}

Anosognosia, the denial of illness, has frequently been described as a symptom of Alzheimer's disease (AD) [14]. It has a major clinical relevance since it is directly related to the reliability of a patient's complaints of dysfunction. Also, a relationship to everyday functioning [5] and treatment outcome [6] has been documented.

Anosognosia is a heterogeneous phenomenon which might be domain-specific [7, 8] and more pronounced for cognitive than for psychiatric and behavioral dysfunction in $\mathrm{AD}$ [9]. Patients can be aware of their dysfunctions but

\section{KARGER \\ Fax +4161306 1234 E-Mail karger@karger.ch} www.karger.com
(C) 2005 S. Karger AG, Basel $1420-8008 / 05 / 0196-0349 \$ 22.00 / 0$

Accessible online at:

www.karger.com/dem
Dr. Elke Kalbe

Max Planck Institute for Neurological Research

Gleueler Strasse 50, DE-50931 Cologne (Germany)

Tel. +49 2214726312, Fax +49 2214726298

E-Mail Elke.Kalbe@pet.mpin-koeln.mpg.de 
may negate their severity [2]. Several sociodemographic, clinical and neuropsychological parameters have been proposed to be associated with self-unawareness in AD. Thus a possible influence of age [2] and gender [5, 11], but not education $[8,10,11]$, on anosognosia has been described (but see Vasterling et al. [8] and Gil et al. [10] for different results concerning the factor age). Some studies found covariance of anosognosia with cognitive functions such as memory $[2,12]$ and executive functioning [13-15]. Depression [12, 16, 17] and anxiety $[2,16]$ have been reported to be inversely related to anosognosia, while agitation and disinhibition are positively correlated to underestimation of dysfunction [16]. Whether longer duration of illness is accompanied by increasing self-unawareness is still under debate $[5,10,18]$. Another important issue is the possible relationship between anosognosia and severity of dementia. Most $[2,3,5,10,15,16$, 19-21] but not all [13, 17, 18, 22] studies documented significant correlations between self-unawareness and overall cognitive functioning in $\mathrm{AD}$, usually operationalized with the Mini Mental State Examination (MMSE [23]) or Clinical Dementia Rating Scale (CDR [24]). For clinical purposes, it appears important to concentrate on AD patients in their earliest stages (MMSE scores $\geq 24$ ) or to examine how representative reports of dysfunctions are in patients with mild cognitive impairment (MCI) which is often regarded as a (pre-)clinical stage of dementia $[25,26]$. A high percentage of these patients converts to dementia, most often to $\mathrm{AD}[27,28]$. In a longitudinal design, Tabert et al. [29] observed that unawareness of functional deficits (activities of daily living - ADL) exists in MCI patients and that it strongly predicts conversion to AD. However, MCI patients with impaired daily living activities might already be considered as very mild AD, and the question remains whether self-estimation of other domains such as cognitive functions is reliable in MCI patients.

The aim of our study was to assess awareness of cognitive dysfunction in patients with very early stages of AD (MMSE scores 224 ) and in subjects with MCI. We further investigated possible correlations of anosognosia with ADL and depressive symptoms - two factors which are both clinically relevant and have proven to be related to self-awareness in AD. For these purposes, a semistructured complaint interview on cognitive domains was administered to patients and caregivers. Using a method which has been established in previous studies [2, 13, 18], the discrepancy between the two reports was taken as a measure of anosognosia.

\section{Materials and Methods}

\section{Subjects}

We included patients meeting criteria for dementia according to DSM-IV [30] as well as NINCDS-ADRDA criteria [31] for probable AD. Severity of dementia was mild in all cases with MMSE scores of $\geq 24$. In a second study group, subjects meeting Petersen criteria [32] for MCI were enrolled in the study. Petersen criteria are (1) subjective memory complaint as elicited by medical history, (2) normal activities of daily living as reported by patients and caregivers in medical history, (3) normal general cognitive function defined as cognitive performance within the range of 1 standard deviation (SD) of normative data in an extensive neuropsychological test battery (see below), (4) abnormal memory for age documented by performance of at least $1 \mathrm{SD}$ below mean normative data in the delayed recall condition of the used verbal or nonverbal memory task (see below), (5) not demented according to DSM-IV [30] criteria and excluded by fulfilling criteria 2 and 3, and (6) absence of psychiatric symptoms assessed during a clinical interview with the patient and a caregiver, and operationalized by the Neuropsychiatric Inventory [33]. The groups were comparable for age, education, and gender. All subjects were recruited in outpatient memory clinics or by referral from general practitioners in a multicenter study of the 5th EU Framework Program Network for Efficiency and Standardization of Dementia Diagnosis (NEST-DD) and gave their written consent according to the study protocol that had been approved by the institutional ethics committee. All patients underwent an extensive neuropsychological, neurological, and physical examination (laboratory tests for thyroid function, vitamin $\mathrm{B}_{12}$ level and folic acid level), and structural and functional brain imaging techniques (magnetic resonance imaging and ${ }^{18} \mathrm{~F}-\mathrm{FDG}$ positron emission tomography). Exclusion criteria for the study included head trauma with permanent brain lesion, hypothyroidism, epilepsy, evidence of psychoactive substance abuse, and systemic disease that could account for disturbance of brain function. For each patient a caregiver or relative, usually spouse or adult child, living with the patient or seeing him weekly, was identified and administered the psychological scales and complaint interview.

\section{Cognitive Testing and Psychological Scales}

The MMSE [23] was used as a global measure of the cognitive status. The neuropsychological test battery included tests for different aspects of memory (California Verbal Learning Test (CVLT) [34], delayed recall of the Rey-Osterrieth-Figure (ROF) [35], digit span forward and reverse [36]), speed of information processing and executive functioning (Trail-Making Test A and B [37]), visuoconstructive abilities (copy of the ROF), word fluency and language comprehension (semantic fluency task 'animals' [35], Token Test from the Aachen Aphasia Test [38]). To describe patients' everyday functioning, the Lawton-Instrumental-Activities-of-Daily-Living (IADL) scale [39] was administered to the patients' caregivers. Noteworthy, the eight items of the IADL scale did not always capture impairment in specific hobbies occurring in very early AD. The 21item Hamilton Depression Rating Scale (HAMD [40]), also administered to caregivers, was taken to measure depressive symptoms.

\section{Complaint Interview}

All patients and caregivers were examined with a structured complaint interview covering 13 cognitive domains (memory, attention, orientation to time, spatial orientation, fluency of speech, 
Table 1. Demographic and clinical characteristics of the $\mathrm{AD}$ and MCI group

\begin{tabular}{llll}
\hline & $\begin{array}{l}\text { AD (n = 82) } \\
\text { mean (SD), range }\end{array}$ & $\begin{array}{l}\text { MCI (n= 79) } \\
\text { mean (SD), range }\end{array}$ & $\mathrm{p}^{1}$ \\
\hline Age, years & $70.2(8.7), 48-85$ & $67.7(8.3), 47-83$ & n.s. \\
Education, years & $10.8(4.5), 4-20$ & $11.1(4.6), 3-20$ & n.s. \\
Age at onset, years & $67.3(9.1), 41-81$ & $65.4(8.3), 45-81$ & n.s. \\
Duration of illness, months & $35.4(23.1), 6-120$ & $29.2(19.7), 10-120$ & n.s. \\
MMSE (max. score = 30) & $25.5(1.3), 24-28$ & $27.0(1.9), 24-30$ & $* * *$ \\
IADL (scale range: 8-31) & $13.1(4.5), 9-26$ & $8.9(1.2), 8-12$ & $* * *$ \\
HAMD (scale range: 0-65) & $4.5(4.1), 0-19$ & $2.8(3.4), 0-20$ & $*$ \\
\hline
\end{tabular}

${ }^{1} \mathrm{p}$ value in two-tailed t test: $\mathrm{ns}=$ not significant, $* \mathrm{p}<0.05, * * * \mathrm{p}<0.001$. word finding, reading, writing, executive functioning, abstract thinking, praxia, number processing, and calculation). For evaluation of each function, a five-stage rating scale was used from 1 = 'no complaints' to 2 = 'mild', 3 = 'moderate', 4 = 'severe' and $5=$ 'very severe impairment'. Functions were exemplified with short questions (e.g. for memory: 'Does it sometimes happen that you forget something when you go to the grocery, that you do not remember where you put the keys or that you do not remember dates that you have?'). The complaint scores of each domain were summed up with a possible score range of 13-65. Conform with previous studies $[2,13,18]$, the discrepancies between patients' and caregivers' total scores and scores in single domains (calculated by subtracting patients' from caregivers' estimations) were taken as measures of anosognosia. Positive values reflect unawareness, with higher values indicating higher degrees of unawareness.

\section{Statistical Analysis}

Statistical analyses were performed with the statistical software package SPSS 10.0 for Windows (SPSS Inc. UK Ltd, Surrey, UK). Parametric methods (two-tailed paired and unpaired t tests, Pearson correlations, stepwise multiple regression analysis) were used for normally distributed data. In case of significant deviations from the normal distribution tested with the Kolmogorov-Smirnov test, non-parametric methods were performed (Mann-Whitney U tests, Kruskal-Wallis H tests, Spearman correlations). We used the $\chi^{2}$ test to compare frequencies.

\section{Results}

\section{Subjects}

Eighty-two AD patients ( 32 male) and $79 \mathrm{MCI}$ subjects (41 male, comparable distribution for sex, $\chi^{2}=2.691$, $\mathrm{p}=0.101)$ were included in the study. Demographic and clinical characteristics of the groups are presented in table 1 . There were no significant differences between the groups regarding age, education, age at onset, and duration of illness. Mean MMSE score was significantly lower in $\mathrm{AD}$ than in $\mathrm{MCI}$ patients $(\mathrm{t}=5.9$, d.f. $=159, \mathrm{p}<0.001)$ but, as defined in the inclusion criteria, reached $\geq 24$ in all cases. In concordance with diagnostic criteria, the IADL scale indicated significantly more impaired ADL functions in the $\mathrm{AD}$ than in the MCI group $(\mathrm{t}=-7.8$, d.f. $=$ $145, p<0.001)$. However, the grade of impairment was only mild even in AD patients. Depressive symptoms (reported by the caregiver) occurred in both groups with significantly higher mean scores in the AD group $(t=-2.7$, d.f. $=157, p=0.017)$ but again with mild level in all cases.

Results of the neuropsychological test battery are indicated in table 2. While the MCI group performed below normative data only in verbal short- and long-term memory (CVLT), impairments in the AD group were observed in multiple memory tasks (CVLT, ROF delayed recall, digit span reverse), visuoconstructive ability (ROF copy), speed of processing and executive functions (Trail-Making Test A and B), word generation (fluency), and understanding verbal instructions (Token Test).

\section{Complaint Interview}

Sum Scores. Results of the complaint interview are shown in figure 1 . AD patients reported significantly less cognitive dysfunction than their caregivers $(21.2 \pm 6.3$ vs. $24.6 \pm 7.3, \mathrm{t}=-4.6$, d.f. $=81, \mathrm{p}<0.001)$. The discrepancy score (caregiver minus patient reports) was above 0 in a majority of $\mathrm{AD}$ subjects (median $=2$, range -18 to 26). In contrast, $\mathrm{MCI}$ patients reported significantly more cognitive dysfunction than their caregivers $(19.8 \pm 5.5$ and $18.5 \pm 4.2, \mathrm{t}=2.2$, d.f. $=78, \mathrm{p}=0.032$ ). Accordingly, the discrepancy score was frequently negative (median $=-1$, range -19 to 12 ).

Between-group comparison revealed comparable sum scores of self-complaints in AD and MCI patients $(\mathrm{t}=$ -1.4 , d.f. $=159, p=0.138)$. In contrast, caregivers of AD patients reported significantly more dysfunctions than caregivers of MCI patients $(t=-6.3$, d.f. $=159, p<0.001)$. 
Table 2. Neuropsychological test battery

\begin{tabular}{lcccc}
\hline & Max. & $\begin{array}{l}\text { AD (n=78) } \\
\text { mean (SD) }\end{array}$ & $\begin{array}{l}\text { MCI (n = 48) } \\
\text { mean (SD) }\end{array}$ & $\begin{array}{l}\text { Normative data } \\
\text { mean (SD) }\end{array}$ \\
\hline CVLT short delay free recall & 16 & $2.4(2.3)^{* * *}$ & $5.2(3.5)^{* * *}$ & $12.1(3.2)^{2}$ \\
CVLT long delay free recall & 16 & $2.2(2.6)^{* * *}$ & $5.4(3.8)^{* * *}$ & $11.2(2.8)^{2}$ \\
Rey-Osterrieth-Figure copy & 36 & $26.1(8.5)^{* *}$ & $31.7(4.5)$ & $33.2(4.0)$ \\
Rey-Osterrieth-Figure delayed recall & 36 & $4.4(4.8)^{*}$ & $10.8(7.5)$ & $16.7(11.8)$ \\
Digit span forward & 12 & $5.7(1.5)$ & $6.2(1.8)$ & $6.9(1.7)$ \\
Digit span reverse & 12 & $4.0(1.9)^{*}$ & $4.7(1.8)$ & $5.9(1.7)$ \\
Trail Making Test Part A (percentile) & 100 & $20.7(22.2)^{*}$ & $39.1(27.6)$ & $50(20)$ \\
Trail Making Test B (percentile) & 100 & $19.2(18.7)^{* *}$ & $37.3(28.4)$ & $50(20)$ \\
Fluency: animals (z-scores) & & $-1.2(0.9)^{*}$ & $-0.5(1.2)$ & $0(1)$ \\
AAT: naming objects & 30 & $28.0(2.6)$ & $29.1(1.5)$ & $28.4(1.8)$ \\
AAT: Token test & 50 (errors) & $2.7(4.8)$ & $0.4(1.3)$ & $1.3(1.6)$ \\
\hline
\end{tabular}

$* 1 \mathrm{SD}, * * 1.5 \mathrm{SD}, * * * 2 \mathrm{SD}$ below normative data.

${ }^{1}$ Performance of control subjects indicated in test manuals.

${ }^{2}$ Data from 34 age-matched healthy controls recruited in different centers participating in the NEST-DD project.

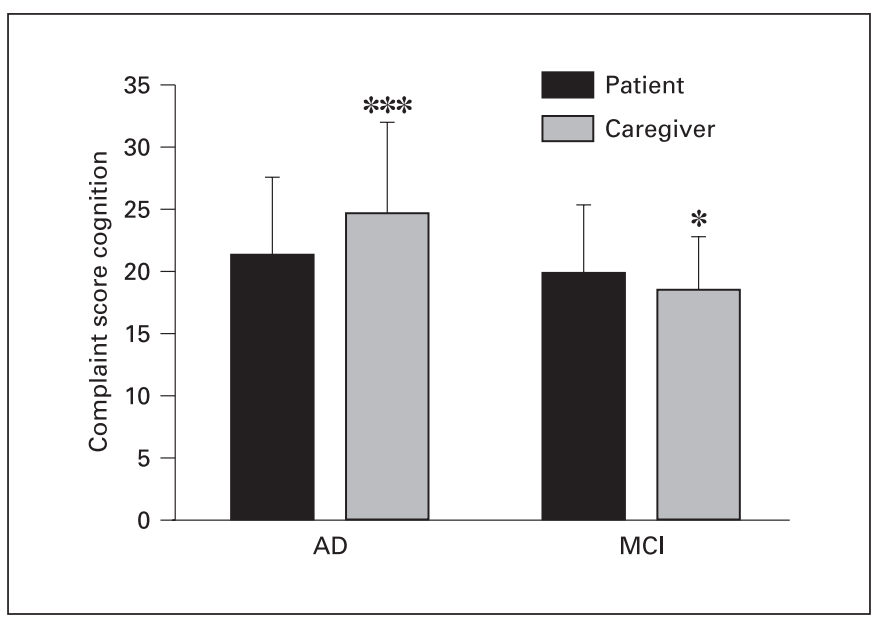

Fig. 1. Results of the complaint interview. Higher complaint scores indicate higher estimations of dysfunction. Significant differences of caregivers' from patients' evaluations are indicated. $* * * \mathrm{p}<$ $0.001, * \mathrm{p}<0.05$.

Accordingly, the discrepancy score was significantly higher in the AD than in the MCI group $(\mathrm{U}=1,854.0, \mathrm{p}<$ $0.001)$.

Analysis of Single Domains. It was first analyzed how many functions were reported to be impaired (neglecting the extent of dysfunction). While caregivers of $\mathrm{AD}$ patients on average reported dysfunctions in $6.5 \pm 3.0$ of all thirteen domains, AD patients found themselves to be impaired in significantly less functions $(4.8 \pm 2.8, \mathrm{t}=$ -4.9 , d.f. $=81, \mathrm{p}<0.001)$. In contrast, MCI subjects evaluated more domains to be deteriorated than their caregivers (self: $4.4 \pm 3.1$, caregiver: $3.7 \pm 2.3, t=3.7$, d.f. $=78$, $\mathrm{p}=0.023$ ). Between-group comparison showed that while caregivers' evaluations significantly differed $(t=-6.5$, d.f. $=159, \mathrm{p}<0.001), \mathrm{AD}$ and $\mathrm{MCI}$ patients' reports were comparable $(t=-0.7$, d.f. $=159, \mathrm{p}=0.455)$.

Secondly the discrepancy between patients' and caregivers' reports in the extent of impairment was examined for each domain (fig. 2). We found significant differences for orientation to space, executive functioning, abstract thinking, and calculation in the AD group. MCI subjects reported significantly more pronounced dysfunction in word finding.

Correlations and Stepwise Regression Analysis. Bivariate correlations and stepwise regression analysis were performed to analyze the relationships of the complaint interview to clinical and sociodemographic variables (table 3). In the $\mathrm{AD}$ group, no relationship was found between reports of dysfunctions and MMSE scores. IADL scores were positively related to caregiver estimations of cognitive dysfunction and to the discrepancy score (both $\mathrm{p}<0.001$, the latter correlation indicating higher degrees of self-unawareness in patients with more IADL dysfunctions). HAMD scores of AD patients were positively associated to self and caregiver estimations of cognitive dysfunctions (so that higher cognitive impairment was reported in more depressed AD subjects), while the dis- 
Fig. 2. Mean discrepancies of patients and caregiver reports of impairment in single functions that were assessed in the interview. Values are calculated by subtracting patients' from caregiver reports with positive values indicating lower estimation of dysfunction in patients (i.e., underestimation of deficit by the patient). Significant deviations are indicated with $* \mathrm{p}<0.05$, $* * * \mathrm{p}<0.001$.

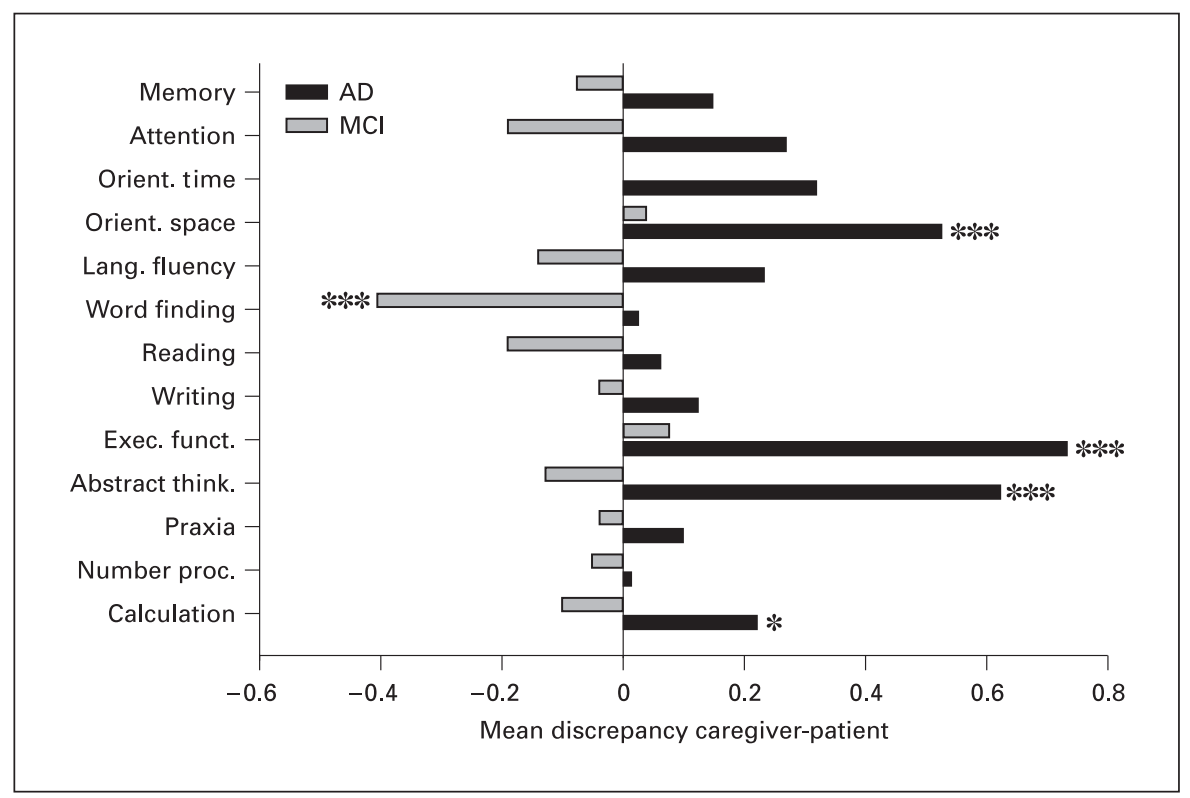

crepancy score was negatively associated with the HAMD ( $p<0.01$, less discrepancy in more depressed AD patients). Age was negatively related to self-reports of dysfunction $(\mathrm{p}<0.01)$, so that younger $\mathrm{AD}$ patients reported more cognitive deficit.

In the MCI group, MMSE scores correlated positively with self-estimations of dysfunctions and negatively with the discrepancy score $(\mathrm{p}<0.05$, indicating more complaints and higher discrepancies in patients with less cognitive deficits). There was a trend for significance ( $\mathrm{p}=$ 0.081 ) for a relationship between self-evaluation of cognitive dysfunction and HAMD. Furthermore, HAMD was significantly related to caregiver evaluations of dysfunctions $(\mathrm{p}<0.05)$. While age was negatively related to selfreports, education was positively related to self and caregivers' estimation of cognitive dysfunction ( $p<0.05$, i.e. a higher rate of cognitive impairment is reported when MCI patients have a higher education). No relationships were found between the interview and duration of illness in either group.

A stepwise regression analysis was performed using self and caregiver evaluations as dependant variables and MMSE, IADL, HAMD scores, age and education as predictive variables. In the $\mathrm{AD}$ group, self-complaints for cognitive dysfunction were significantly explained by the factor age $(\mathrm{p}=0.006)(\mathrm{F}=8.102, \mathrm{R} 2=0.106)$ while caregiver reports were dependent on IADL $(\mathrm{p}=0.002)$ and $\operatorname{HAMD}(\mathrm{p}=0.002)(\mathrm{F}=16.917, \mathrm{R} 2=0.336, \mathrm{p}<0.001)$. In the MCI group, self-reports of dysfunction were pre-
Table 3. Correlations of self and caregiver ratings and of discrepancy scores in the complaint interview with psychological scales, demographic and clinical variables

\begin{tabular}{|c|c|c|c|}
\hline & $\begin{array}{l}\text { Patient } \\
\text { estimation } \\
\text { cognition, r }\end{array}$ & $\begin{array}{l}\text { Caregiver } \\
\text { estimation } \\
\text { cognition, r }\end{array}$ & $\begin{array}{l}\text { Discrepancy } \\
\text { score cognition } \\
\text { rho }\end{array}$ \\
\hline \multicolumn{4}{|l|}{ MMSE } \\
\hline $\mathrm{AD}$ & 0.15 & 0.15 & 0.01 \\
\hline MCI & $0.28 *$ & -0.15 & $-0.36^{* *}$ \\
\hline \multicolumn{4}{|l|}{ IADL } \\
\hline $\mathrm{AD}$ & 0.07 & $0.47 * * *$ & $0.41 * * *$ \\
\hline MCI & 0.18 & 0.18 & 0.03 \\
\hline \multicolumn{4}{|l|}{ HAMD } \\
\hline $\mathrm{AD}$ & $0.24 *$ & $0.48^{* *}$ & $-0.23 * *$ \\
\hline MCI & 0.19 & $0.23^{*}$ & -0.01 \\
\hline \multicolumn{4}{|l|}{ Age } \\
\hline $\mathrm{AD}$ & $-0.33^{* *}$ & -0.11 & 0.15 \\
\hline MCI & $-0.28^{* *}$ & -0.16 & $0.25^{*}$ \\
\hline \multicolumn{4}{|c|}{ Education } \\
\hline AD & 0.10 & 0.16 & 0.13 \\
\hline MCI & $0.28 *$ & $0.29 * *$ & -0.10 \\
\hline \multicolumn{4}{|c|}{ Disease duration } \\
\hline $\mathrm{AD}$ & 0.13 & -0.19 & -0.13 \\
\hline MCI & -0.12 & -0.14 & -0.05 \\
\hline
\end{tabular}

Dement Geriatr Cogn Disord 2005;19:349-356 
dicted by the factors age $(p<0.001)$ and HAMD ( $p=$ $0.002)(F=6.714, R 2=0.157)$. Caregiver reports were solely explained by the patients' education $(F=5.390$, $\mathrm{R} 2=0.056, \mathrm{p}=0.023)$.

\section{Discussion}

Our results suggest that anosognosia measured by a discrepancy between self and caregiver reports of dysfunction is a frequent symptom in very mild AD (MMSE $\geq 24$ ) but not in MCI.

Most [2, 3, 5, 10, 15, 16, 19-21] but not all [13, 17, 18, 22] previous studies examining anosognosia in $A D$ showed a relationship between diminished self-insight and dementia severity but usually did not include mild $\mathrm{AD}$ patients with MMSE scores of $\geq 24$. In contrast to our findings, Zanetti et al. [20], who examined AD patients from mild to severe stages of disease, found high self-awareness of function in mildly affected patients (MMSE 224 ) but linear decline of insight from moderate (MMSE 13-23) to severe stages (MMSE $\leq 12$ ) of disease. The inconsistency may be due to methodological differences (smaller patient sample, other insight scales). In our early stage AD sample, no relationship was found between the 'anosognosia score' and MMSE score. However, anosognosia measurement had a high clinical relevance, since everyday functioning measured by the IADL was a clear predictor for lack of insight both in our study and in that of Migliorelli et al. [5]. Finally, in line with previous studies [8], our results suggest that age, education, and disease duration are unrelated to self-unawareness in AD.

Other studies examining awareness of single functions revealed that lack of insight might be domain-specific [7]. Our own analyses confirm that the degree of awareness is variable for different cognitive abilities and that underestimation of dysfunction in mild $\mathrm{AD}$ is prominent for executive functions (which have been documented to be closely linked to self-awareness [13-15]), and abstract thinking. The remarkable finding that memory was not judged differentially by our AD patients and their caregivers suggests that lack of insight into memory impairment might develop in later stages of the disease and possibly explains the relationship between dementia severity and anosognosia revealed in other studies.

For our MCI sample we found that patients reported more cognitive impairment compared to their caregivers. Thus either MCI patients' self-reports might not be reliable or they might feel more cognitive difficulties than noticed by their caregivers. Previous findings already suggested that self-reports are not a reliable measure to reflect past, current or future dysfunction in age-associated memory impairment, mild cognitive disorder and agingassociated cognitive decline [41, 42]. However, misjudgements of dysfunction in such patients have usually been found in the sense of an underestimation. Albert et al. [43] examined self and informant reports of functional abilities in patients with minimal cognitive impairment $(\mathrm{CDR}=0)$ and questionable dementia $(\mathrm{CDR}=0.5)$ and detected comparable complaints among both groups but lower correlations for self versus informant reports in $\mathrm{CDR}=0.5$ patients indicating an underestimation of deficits. Tabert et al. [29] studied MCI patients using a longitudinal design and found that discrepancies between informants' and patients' reports of dysfunction occurred in a subgroup of their patients and (retrospectively) predicted future diagnosis of AD. Differences in the inclusion criteria of patients should be considered as a possible source of inconsistencies in the results. While our MCI patients by definition had memory complaints and dysfunctions but performed within a normal range in everyday functioning, Tabert et al. [29] defined MCI in a broader sense as cognitive deficits that exceed benign aging but are not severe enough for dementia diagnosis and used ADL dysfunctions as their main outcome measure. In another study, Vogel et al. [44] observed that impaired insight in memory dysfunction was equally frequent in patients with mild $\mathrm{AD}$ and amnesic MCI (with CDR scores of 0.5 for both groups). Again, inclusion criteria for the MCI group differed to ours in that subjective memory complaints were not obligatory in their patients. Additionally, lower mnestic functions were required (2 SDs in their study versus $1 \mathrm{SD}$ below mean normative data in our study) and lower cognitive functions were allowed (up to $2 \mathrm{SD}$ in their study versus $1 \mathrm{SD}$ below normative data in our study). To summarize, our MCI sample compared to those in former studies is characterized by higher cognitive and everyday functioning and minor memory deficits. Thus, while MCI patients with more pronounced memory deficits and minor cognitive functions (which are at the lower edge of the 'normal range') are more likely to underestimate or even neglect their deficits, 'high functioning' MCI patients as examined in our study seem to be highly critical (or even too critical) concerning their cognitive functions.

In our MCI group self but not caregivers' dysfunctions correlated with MMSE scores. This might reflect subtle deficits that are recognized only by the patients themselves but which have no overt impact on global cognitive 
evaluation or on everyday functioning (also questioning how reliable caregiver reports are, see discussion below). However, this relationship of self-report and MMSE was positive suggesting that patients have a most critical view on their performance especially in the earliest phase of disease. Alternately, lesser cognitive complaint in MCI patients with lower MMSE score might reflect very early anosognosia in patients more likely to evolve to AD.

Several factors influence self and caregiver evaluation of dysfunction. Age has an impact on self-estimation with younger patients reporting more cognitive dysfunction. Possibly deficits in younger patients contrast more obviously with premorbid functioning. Also, older patients may tend to consider deficits as a benign aging process. Different from previous studies [8,10,11], our data suggest that higher education is associated with more self and caregiver reports of dysfunction at least for MCI patients, probably indicating that deficits are more evident in high educated individuals. In line with the literature $[12,16$, 17], we found that depressive symptoms measured by HAMD correlated to self-evaluations in the AD group and constituted a predictor of self-reports in the MCI group leading to high estimation of cognitive impairment. Noteworthy, major depression was excluded in our subjects, and depressive symptoms were lower in our MCI than in our AD group (see table 1). Finally, the result that caregivers' reports of cognitive dysfunction is linked to depression points to the methodological question of how reliable informants' reports are. Zanetti et al. [45] demonstrated that caregivers' view on their relatives' functional state is influenced by caregivers' burden and should thus be regarded as a subjective measure. Consequently the use of discrepancy scores for the study of anosognosia seems somewhat limited [46]. However, several studies suggest that informant complaints are much more reliable than individual complaints [17, 41, 42], and that informant reports of memory loss distinguished nondemented from demented individuals and predicted later development of AD [47].

From a clinical point of view, our finding that $\mathrm{AD}$ and MCI patients' self-evaluations of cognitive dysfunction are comparable is of utmost relevance. It alerts the clinician to the fact that self-reports of impairments even in mildly affected patients cannot be regarded as reliable and might constitute an overestimation (most probably in MCI patients) or an underestimation (in AD patients) of the actual clinical impairment; moreover, self-evaluation is influenced by different factors such as age and affect.

In summary, while most MCI patients tend to overestimate impairments, anosognosia in the sense of an underestimation of dysfunction must be regarded as a clinical symptom of very mild AD (MMSE scores of $\geq 24$ ). We conclude that medical history even in mildly affected patients should always include information both from the patient and the caregiver.

\section{Acknowledgements}

This study was supported by the 5th EU Framework Program (NEST-DD). We thank X. Delbeuck and P. Marique for their contribution in collecting neuropsychological data.

\section{References}

1 Agnew SK, Morris RG: The heterogeneity of anosognosia for memory impairment in Alzheimer's disease: A review of the literature and a proposed model. Aging Ment Health 1998;2: $7-19$.

2 Derouesné $\mathrm{C}$, Thibault $\mathrm{S}$, Lagha-Pierucci $\mathrm{S}$, Baudouin-Madec V, Ancri D, Lacomblez L: Decreased awareness of cognitive deficits in patients with mild dementia of the Alzheimer type. Int J Geriatr Psychiatry 1999;14:1019_ 1030

3 Wagner MT, Spangenberg KB, Bachman DL, O'Connell P: Unawareness of cognitive deficit in Alzheimer disease and related dementias. Alzheimer Dis Assoc Disord 1997;11:125131.

4 Mullen R, Howard R, David A, Raymond L: Insight in Alzheimer's disease. Int J Geriatr Psychiatry 1996;11:645-651.
5 Migliorelli R, Teson A, Sabe L, Petracca G, Petracchi M, Leiguarda R, Starkstein SE: Anosognosia in Alzheimer's disease: A study of associated factors. J Neuropsychiatry Clin Neurosci 1995;7:338-344.

6 Koltai DC, Welsh-Bohmer KA, Schmechel DE: Influence of anosognosia on treatment outcome among dementia patients. Neuropsychol Rehabil 2001;11:455-475.

7 Starkstein SE, Sabe L, Chemerinski E, Jason L, Leiguarda R: Two domains of anosognosia in Alzheimer's disease. J Neurol Neurosurg Psychiatry 1996;61:485-490.

8 Vasterling JJ, Seltzer B, Watrous WE: Longitudinal assessment of deficit unawareness in Alzheimer's disease. Neuropsychiatry Neuropsychol Behav Neurol 1997;10:197-202.

9 Kotler-Cope S, Camp CJ: Anosognosia in Alzheimer disease. Alzheimer Dis Assoc Disord 1995;9:52-56.
10 Gil R, Arroyo-Anllo EM, Ingrand P, Gil M, Neau JP, Ornon C, Bonnaud V: Self-consciousness and Alzheimer's disease. Acta Neurol Scand 2001;104:296-300.

11 Sevush S, Leve N: Denial of memory deficit in Alzheimer's disease. Am J Psychiatry 1993; 150:748-751.

12 Feher EP, Roderick K, Mahurin K, Inbody SB, Crook TH, Pirozzolo FJ: Anosognosia in Alzheimer's disease. Neuropsychiatry Neuropsychol Behav Neurol 1991;4:136-146.

13 Michon A, Deweer B, Pillon B, Agid Y, Dubois B: Relation of anosognosia to frontal lobe dysfunction in Alzheimer's disease. J Neurol Neurosurg Psychiatry 1994;57:805-809.

14 Lopez OL, Becker JT, Somsak D, Dew MA, DeKosky ST: Awareness of cognitive deficits and anosognosia in probable Alzheimer's disease. Eur Neurol 1994;34:277-282. 
15 Ott BR, Lafleche G, Whelihan WM, Buongiorno GW, Albert MS, Fogel BS: Impaired awareness of deficits in Alzheimer disease. Alzheimer Dis Assoc Disord 1996;10:68-76.

16 Harwood DG, Sultzer DL, Wheatley MV: Impaired insight in Alzheimer disease: Association with cognitive deficits, psychiatric symptoms, and behavioral disturbances. Neuropsychiatry Neuropsychol Behav Neurol 2000; 13:83-88.

17 Förstl H, Geiger-Kabisch C, Sattel H, Besthorn C, Schreiter-Gasser U, Abrahams CM, Biedert S: Self-rating and informant's rating of clinical disorders in Alzheimer's disease. Fortschr Neurol Psychiat 1996;64:228-233.

18 Seltzer B, Vasterling JJ, Mathias CW, Brennan A: Clinical and neuropsychological correlates of impaired awareness of deficits in Alzheimer disease and Parkinson disease: A comparative study. Neuropsychiatry Neuropsychol Behav Neurol 2001;14:122-129.

19 Sevush S: Relationship between denial of memory deficit and dementia severity in Alzheimer disease. Neuropsychiatry Neuropsychol Behav Neurol 1999;12:88-94.

20 Zanetti O, Vallotti B, Frisoni GB, Geroldi C, Bianchetti A, Pasqualetti P, Trabucchi M: Insight in dementia: When does it occur? Evidence for a nonlinear relationship between insight and cognitive status. J Gerontol B Psychol Sci Soc Sci 1999;54:P100-P106.

21 McDaniel KD, Edland SD, Heyman A, Investigators CC: Relationship between level of insight and severity of dementia in Alzheimer disease. Alzheimer Dis Assoc Disord 1995;9: 101-104.

22 Starkstein SE, Sabe L, Cuerva AG, Kuzis G, Leiguarda R: Anosognosia and procedural learning in Alzheimer's disease. Neuropsychiatry Neuropsychol Behav Neurol 1997;10:96101

23 Folstein MF, Folstein SE, McHugh PR: 'Minimental state'. A practical method for grading the cognitive state of patients for the clinician. J Psychiatr Res 1975;12:189-198.

24 Hughes CP, Berg L, Danziger WL, Coben LA, Martin RL: A new clinical scale for the staging of dementia. Br J Psychiatry 1982;140:566572 .

25 Petersen RC, Doody R, Kurz A, Mohs RC, Morris JC, Rabins PV, Ritchie K, Rossor M, Thal L, Winblad B: Current concepts in mild cognitive impairment. Arch Neurol 2001;58: 1985-1992.
26 Shah Y, Tangalos EG, Petersen RC: Mild cognitive impairment. When is it a precursor to Alzheimer's disease? Geriatrics 2000;55:62, 65-68.

27 Sramek JJ, Veroff AE, Cutler NR: The status of ongoing trials for mild cognitive impairment. Expert Opin Investig Drugs 2001;10 741-752.

28 Larrieu S, Letenneur L, Orgogozo JM, Fabrigoule $\mathrm{C}$, Amieva $\mathrm{H}$, Le Carret N, BarbergerGateau P, Dartigues JF: Incidence and outcome of mild cognitive impairment in a population-based prospective cohort. Neurology 2002;59:1594-1599.

29 Tabert MH, Albert SM, Borukhova-Milov L, Camacho Y, Pelton G, Liu X, Stern Y, Devanand DP: Functional deficits in patients with mild cognitive impairment: Prediction of $\mathrm{AD}$. Neurology 2002;58:758-764.

30 American Psychiatric Association: Diagnostic and Statistical Manual of Mental Disorders, ed 4. APA, 1994.

31 McKhann G, Drachman D, Folstein M, Katzman R, Price D, Stadlan EM: Clinical diagnosis of Alzheimer's disease: Report of the NINCDS-ADRDA Work Group under the auspices of Department of Health and Human Services Task Force on Alzheimer's Disease. Neurology 1984;34:939-944.

32 Petersen RC, Smith GE, Waring SC, Ivnik RJ, Tangalos EG, Kokmen E: Mild cognitive impairment: Clinical characterization and outcome. Arch Neurol 1999;56:303-308.

33 Cummings JL, Mega M, Gray K, RosenbergThompson S, Carusi DA, Gornbein J: The Neuropsychiatric Inventory: Comprehensive assessment of psychopathology in dementia. Neurology 1994;44:2308-2314.

34 Delis DC, Kramer JH, Kaplan E, Ober BA California Verbal Learning Test, Adult Version. San Antonio, The Psychological Corporation, 1987.

35 Spreen O, Strauss E: A Compendium of Neuropsychological Tests: Administration, Norms, and Commentary. New York, Oxford University Press, 1998.

36 Wechsler D: Wechsler Memory Scale, ed 3. San Antonio, The Psychological Corporation, 1997.
37 Reitan R, Wolfson D: The Halstead-Reitan Neuropsychological Test Battery, Theory and clinical interpretation. Tucson, Neuropsychology Press, 1993.

38 Huber W, Poeck K, Willmes K: The Aachen Aphasia Test. Adv Neurol 1984;42:291-303.

39 Lawton MP, Brody EM: Assessment of older people: Self-maintaining and instrumental activities of daily living. Am J Psychiatry 1969; 154:609-615.

40 Hamilton M: Development of a rating scale for primary depressive illness. Br J Soc Clin Psychol 1967;6:278-296.

41 Jorm AF, Christensen H, Korten AE, Henderson AS, Jacomb PA, Mackinnon A: Do cognitive complaints either predict future cognitive decline or reflect past cognitive decline? A longitudinal study of an elderly community sample. Psychol Med 1997;27:91-98.

42 Carr DB, Gray S, Baty J, Morris JC: The value of informant versus individual's complaints of memory impairment in early dementia. Neurology 2000;55:1724-1726.

43 Albert SM, Michaels K, Padilla M, Pelton G, Bell K, Marder K, Stern Y, Devanand DP: Functional significance of mild cognitive impairment in elderly patients without a dementia diagnosis. Am J Geriatr Psychiatry 1999;7: 213-220.

44 Vogel A, Stokholm J, Gade A, Andersen BB, Heijl AM: Awareness of deficits in mild cognitive impairment and Alzheimer's disease: Do MCI patients have impaired insight? Dement Geriatr Cogn Disord 2004; 17:181-187.

45 Zanetti O, Geroldi C, Frisoni GB, Bianchetti A, Trabucchi M: Contrasting results between caregiver's report and direct assessment of activities of daily living in patients affected by mild and very mild dementia: The contribution of the caregiver's personal characteristics. J Am Geriatr Soc 1999;47:196-202.

46 Lamar M, Lasarev MR, Libon DJ: Determining levels of unawareness in dementia research. J Neuropsychiatry Clin Neurosci 2002;14: 430-437.

47 Tierney MC, Herrmann N, Geslani DM, Szalai JP: Contribution of informant and patient ratings to the accuracy of the Mini Mental State Examination in predicting probable Alzheimer's disease. J Am Geriatr Soc 2003; 51:813818 